vears would be required for the complete change-over, and the longer the period of change-over the lower the total transitional costs. Educational benefits are real, but are not easily measurable in terms of money. The Committees stress the existence of a general feeling that the metric system will in course of time become more widely used in the rest of the world and the United Kingdom. They recommend, therefore, a regular two-yearly review by the Board of Trade in consultation with industry and commerce, and in conjunction with corresponding bodies in the Commonwealth and the United States, and paying particular attention to trends in Japan and India and the under-developed countries of Asia and Africa. These reviews should indicate what stimulus might be given to more rapid change-over to the metric system in the United Kingdom and in what soctions of industry and commerce metric usage could be introduced with most benefits and the least transitional dislocations. It is suggested that there may be a case for the British Standards Institution pub. lishing further metric standards to facilitate manufacture in metric dimensions for export.

The Committees agree that there is real advantage to be gained now by increased rationalization of the Imperial system, and they recommend that this should be further studied. This is a specialist matter for each industry ; but they suggest that all Govern- ment departments and nationalized industries could examine the practicability of eliminating intermediate units of weight between the ton and the pound avoirdupois ; alternatively, use of the cental $(100 \mathrm{lb}$.) should be encouraged in place of the hundredweight, and there should be a short ton of $2,000 \mathrm{lb}$. in place of the long ton of $2,240 \mathrm{lb}$. They also recommend that the apothecaries' troy and pennyweight systems be removed from school curricula, and that the rod, pole or perch of $5 \frac{1}{2}$ yards and the corresponding square measure of 301 square yards be officially abolished, and that use of the decimalized inch in place of fractions be increased. Finally, under educational aspects, they recommend that even if no action be taken on decimal coinage or the metric system, much greater emphasis should be placed forthwith on the teaching and use of decimals and the metric system in the educational curriculum of Britain from the earliest stages. This would not only promote 'decimal thinking' at an earlier age than at present, but would also be of value to entrants into industry and commerce, where the practical use of decimals is increasing.

Appendixes to the report present extracts from evidence received on decimal coinage and the metric system, and group the countries of the world according to their adoption or not of the metric system.

\title{
SELECTION OF EXECUTIVES
}

$\mathrm{D}$ URING the years immediately after the Second World War, it was the fashion for amateur and professional psychologists to see 'significance' in a great variety of phenomena, from handwriting to the choice of a wife, from remarks made during a group discussion to readiness to become angry at an interview, from imagined shapes seen in an ink-blot to the design created with a set of mosaics. That any one of these actions can be significant of itself was an assumption which has invalidated much of the psychology of personality testing during the past ten years, and such is the subject of a recent article in the European Productivity Agency Bulletin (No. 34 ; February 1960).

The recent trend has been a healthy one. Amateur psychologists are not so respected in their assessment of significant revelations. Professional psychologists have considerably limited their claims and disciplined their methods, thereby increasing their effectiveness. But much indisciplined personality testing still goes on. Recently, a works manager was appointed solely on the judgment of the managing director's wife's interpretation of the applicant's handwritten signature to a typewritten letter. A brilliant technologist was rejected in favour of a less-qualified man because he did not take a lead in a discussion with other candidates during a specially organized hotel dinner. A psychiatrist employed by a large organization in London interviews candidates for the higher staff grades and deliberately sets out to anger them, judging from the time it takes them to lose their tempers whether or not they have initiative.

Warren Lamb suggests that it is an imposition to subject a candidate to having his individual actions judged as to their significance and what they reveal without being able to defend himself. The existence of significance testing is due to two fallacies under- lying the most scrupulous application of pure psychological research within industry and commerce: (a) that a test situation can be so devised that the candidate's response will be identical with what it would be on other occasions ; $(b)$ that a quality once measured (for example, dominance, perseverance) will apply in all conditions.

Validating procedures have so narrowed down the aims under $(a)$ that the results of properly validated present-day performance tests are so prescribed as to make only a minor contribution to industrial selection and appraisal. The simplest of casual observation will dispose of $(b)$. One would not have to search far to find the dominant business man and the submissive husband. A recent survey of top-ranking business executives in England revealed that the greatest common characteristic was extreme shyness.

Is it possible to have any form of personality testing which does not depend upon attributing significance to any one action or response? One method has been devised based on an analysis of constant elements in a person's movements.

No two people move in exactly the same way; in habitual adjustments of posture, gestures, handling of objects, a way of walking and so on, there are distinct individual differences. It has been found that everyone has certain movement co-ordinations which are constant to all his activities. That is to say, there are certain elements in the total movement which remain constant whatever the person's behaviour or emotion. For example, these elements will remain constant during an occasion when the person is sitting relaxed enjoying a casual conversation, and on another occasion when he is giving a demonstrative, angry, fiery political speech. Sets of observations taken on each occasion, and analysed separately, produce an identical result. 
A person's movements are different on varying occasions. It is only part of his movement-a part even of each action - which remains constant. The full range of the constant elements will never be present in any one action. A large number of observations are needed, based on a statistical sampling method in order to have sufficient data to analyse. It has proved practicable to obtain this data in the course of a normal business interview.

The development of this work needed a more penetrating investigation into the details of a movement than has usually been the case with other investigations. The present methods have been made possible by the work of Rudolph Laban. The codification of the elements of movement upon which Laban established his notation has made it possible to record the process of variation of at least seven different movement components occurring simultaneously in the course of one action.

Movement analysis reveals those capabilities which can be expressed spontaneously. A person who can present himself or exercise authority spontaneously would not have to depend upon 'props' such as the correct dress or a conferred status. A distinction can be made between those whose authority is fixed, dependent upon a static set of eircumstances, and who would have little range of the relevant movement variation, and those whose authority is spontaneous and adaptable, and who would have a good range of variation.

If a person is asked to perform a number of actions unassociated with any particular purpose and built up from within his range of constant elements, he enjoys the movement. If he is asked to perform actions built up from outside the range, he invariably feels awkward and unco-ordinated. Many experiments with people of many different vocations have shown this to be true. The range of constant elements is the range within which a person 'feels right'.

That there is a relationship between mental functioning and physical movement is implied in the development of psychosomatic medicine during the course of the present century.
The application of this work within industry has been on the basis that if a person is able to work within a set of conditions by meeting the needs from within his range of constant elements (that is to say, the range within which he 'feels right'), then he has aptitude for that set of conditions. This gives $a_{0}$ precise definition to what is meant by 'aptitude', a word which is often used loosely as a synonym for ability, potentiality, capacity or even intelligence.

In order to make an 'aptitude assessment', it is necessary to specify the particular set of conditions, and this is done according to current techniques of job evaluation, differentiating between those aspects of the job which can be satisfied through purely technical competence and those aspects which can be met effectively only through the appropriate aptitude. It is obvious, but often little considered, that a man of a certain technical competence may be able to apply his skill effectively in one set of conditions and ineffectively in another. The aptitude assessment which derives from the analysis of constant elements in movement is a measure of a person's readiness to apply his technical skills or knowledge within a specified set of conditions.

Whereas much investigation of the 'significant response' type seeks to classify phenomena, reduces differences and generalizes, the methods of aptitude assessment based on movement observation follow a contrasting procedure. There is no classification of phenomena, differences are magnified, both within the individual and the conditions, and the resultant assessment is a particular yardstick, applying only within specified conditions. The procedure brings forward the exceptional, distinctive 'man of the moment', as against the average, conformist 'type for the job'.

The procedure is not itself exceptional and is akin to existing practices. An appreciation of the techniques is easily gained during practical study. A number of intensive two-week courses have successfully been given to executives wishing to incorporate the techniques within their own company practices.

T. H. HAWKINS

\section{SCOPE FOR EXPANDING PULP AND BOARD INDUSTRIES IN BRITAIN}

\begin{abstract}
$\mathrm{T}$ $\mathrm{HE}$ conclusions and recommendations of two reports prepared by Sandwell and Co., Ltd., on pulp and board mills in Great Britain (see Nature, March 26, p. 894) were used as the basis of a discussion organized by the Society of Foresters of Great Britain and held during November of last year. This Society is concerned with "the knowledge of technical forestry in all its aspects" and it was fitting that on this, the first, of its ventures into special discussion meetings it decided to examine the implications of the Sandwell reports. The proceedings of this meeting have now been published as a supplement to the Society's journal, Forestry, which is available to nonmembers*. The programme was designed to give a balanced picture of the problems involved in development and the individual views of industrialists,
\end{abstract}

* The Development of Pulp and Particle Board Industries and Their Effect on Forest Management. Pp. 68. (Oxford University Press, 1960.) $5 s$. technologists, and competitors for the wooden raw material. 'The growers' point of view was discussed under forest management considerations and the whole idea was subjected to the economist's evaluation, and a careful summing up.

As the Society of Foresters of Great Britain included few industrialists in its membership, invitations were sent to leading personalities in the industries concerned. Dr. T. H. Frankel, of Sudbrook Pulp Mill, Ltd., a subsidiary of Wiggins Teape and Co., Ltd., said that in his view the Sandwoll reports implied that the smaller the mill the less efficient it would be. In exploring the possibility of setting up a pulp mill in the Scottish Highlands, he stressed the unlikelihood of a newsprint mill being sited in Britain. $\mathrm{He}$ examined some of the technical and economic problems of the industry and urged that the criterion for growers of timber should be to produce the maximum bone-dry weight, bark free, per acre per 